\title{
Interview
}

\section{ISU Interviews I: Dr. Daniel U. Wilde}

(Director of NERAC, and immediate past President of the Association of Information and Dissemination Centers)

$I S U$ : To begin this interview, I would like our readers to have some information on your personal background. This will provide them with a perspective for your role as a leader in the information distribution community in the United States.

Wilde: My college education was in the electrical engineering area. In graduate school at M.I.T., I became interested in the use of computers to solve problems.

$I S U$ : Your present work is as Director of the New England Research Application Center located at the University of Connecticut in Storrs?

Wilde: Yes, but because we have many contacts outside New England, we have been emphasizing the acronym 'NERAC'.

ISU: Prior to joining NERAC, what was your working background?

Wilde: Primarily I was a teacher of computer applications courses in the Business School of the University of Connecticut, but I was also part-time as Assistant Director of NERAC for computer operations.

$I S U$ : How long have you been Director of NERAC?

Wilde: Since 1972.

ISU: Has NERAC been a member of ASIDIC since it was founded?

Wilde: No. In fact I was the first person from NERAC that became active in ASIDIC. It has always been very clear to me that, in order to perform our (NERAC's) work, we had to have access to many information sources. ASIDIC is the US organization that brings data base producers and data base users together in a common forum.

ISU: How long were you President of ASIDIC?

Wilde: I served two one-year terms but I was Secretary-Treasurer for two years before that. Of course I remain on the Board as immediate past President.

$I S U$ : Will you describe ASIDIC for us in terms of its membership and administraton?

Wilde: ASIDIC is an organization of organizations. It has no individual 0167-5265/82/0000-0000/\$02.75 @ 1982 North-Holland 
memberships. There are three components: data base producers, systems suppliers or 'spinners', and industrial, academic and governmental organizations that make high use of data base information. In the past ten years we have seen an increase in the number of producers and a decrease in organizations that use information on their own (in-house) facilities. This has shifted ASIDIC from a balanced organization to one that is heavier on the data base producer side.

ISU: What are the present proportions of the ASIDIC membership 'mix'?

Wilde: I would guess that it is approximately 50\% data base producers, $30 \%$ systems suppliers, and 20\% users.

ISU: Do you feel that this shift has helped or hurt the organization?

Wilde: I think that it is getting harder to find user organizations that understand their stake in data bases from a production and manipulation point of view. This has hurt ASIDIC, but it is also the nature of the information business and its evolutionary status due to new technologies.

ISU: Would you depict ASIDIC membership as shrinking, growing or stable in terms of numbers?

Wilde: I would say that it is growing slightly. Unfortunately the membership distribution is not the way I would like to see it. Our real problem is that we don't have many people from industry who really understand data bases and can keep the other two segments open, honest and truthful.

$I S U$ : What is the administrative structure for the operation of ASIDIC?

Wilde: The governing body of ASIDIC is an Executive Committee made up of an elected President and four members. After each election, the Committee selects a Secretary-Treasurer. There is a Planning Committee, a Program Committee which organizes two semi-annual meetings of ASIDIC, an Education Committee, a Standards Committee, and a Publication Committee which handles our newsletter. Of course there are ad hoc committees that take on particular tasks from time to time.

$I S U$ : Can you give us a rough idea of the actual numbers of ASIDIC members?

Wilde: There are presently 110-115 organizations in ASIDIC. About 25-35 are associate members primarily from outside the United States. There are approximately 35 data base producers, 15 systems suppliers and 10 industrial companies.

$I S U$ : Can you give us an estimate of the annual budget for ASIDIC?

Wilde: The budget is relatively modest at about $\$ 15,000$ per year. Of course ASIDIC is largely a volunteer organization with only a part-time paid secretary.

ISU: What are the membership fees for ASIDIC?

Wilde: Full members pay $\$ 50.00$ per year, and associates $\$ 30.00$. Other revenues come to ASIDIC from the two meetings.

ISU: Would you tell us what you consider to be the ASIDIC mission or charter?

Wilde: I think that ASIDIC's mission is to provide the three groups an opportunity to come together every six months to explore issues that have been identified as coming up on the horizon in the industry. For example one issue that has been on everyone's mind in the last two years is the problem of re-use of information. This has boiled down to be an essentially economic problem of how 
everyone in the information chain is to maintain economic viability. Other issues have been concerned with documentation, reasonable pricing policies etc. Issues have come to the group's attention, have been discussed, and-in general-solutions have been agreed on. Then the organization has moved on to new issues.

$I S U$ : Do you think that the ASIDIC tendency to shift ground after doing often very good work to achieve consensus has been the proper policy?

Wilde: I think that it would be very difficult to get $100 \%$ agreement on any issue. What we encourage is allowing our members to be very forthright- to speak out on issues. It gives other people time to listen, understand and accept varying positions. We must remember that in this industry most agreements are bi-lateral, or one-on-one. It has been ASIDIC practice not to dictate to its members what the terms of these agreements should be, but to help members move to a commonly accepted ground.

$I S U$ : Given that position, there are long periods when major issues such as you describe are absent. Doesn't this lend a certain 'peaks and valleys' nature to the deliberations of ASIDIC?

Wilde: That is certainly true. You would notice, if you reviewed the meetings of the past ten years, that there are periods where ASIDIC reverts to an educational mode for its members. Programs on new technology or on new developments outside the United States substitute for programs on major issues.

ISU: What is the ASIDIC position with reference to its relationships with similar organizations elsewhere? Particularly with EUSIDIC?

Wilde: There is a lot of cross-fertilization between ASIDIC and EUSIDIC. Many organizations are members of both. I personally have tried to act as a communications link; but, I think that the lack of intimacy between the two organizations comes from differing crises. An example might be the past preoccupation of EUSIDIC with telecommunications. When I spoke to ASIDIC members as to their interest in this area, the level of telecommunications was so different in the US that it simply wasn't considered a problem.

$I S U$ : Do you think that the separation by function that we see in Europe where distribution centers and data base producers have separate organizations, is a barrier to information exchange?

Wilde: In general, I believe that the industry has benefited when there is good communications between and among concerned organizations. I believe that this is the case regardless of geography.

$I S U$ : Well, that is certainly a statesmanlike reply.

Wilde: Let me add that I would like to encourage Europeans to consider joining ASIDIC so that they could acquire an understanding of American problems and therefore be in a better position to exploit the American market.

$I S U$ : In that context, what do you see as the major issues that ASIDIC will address in the next five years?

Wilde: Let me begin by saying that I think the current issue facing the organization and its membership has to do with the problem of the packaging and re-use of information.

Approximately two years ago this issue came on the scene. At that time the 
user community appeared willing to exploit data bases to the fullest without consideration of the compensation and long range viability of data base producers. ASIDIC has had three meetings on the subject and there has been a pronounced shift in attitudes. We have now come to a common ground that these things were going to be done. Many of our speakers have said that this is a very positive thing for the industry. Attendees at the last conference agreed that data base producers should be compensated to insure their viability in the future; it was agreed that this was a matter of coming up with a fair and equitable pricing policy. I think honestly that from ASIDIC's membership point of view, this issue has been resolved.

I think that the next issue will be the future of information services in general. This will be addressed at the next meeting, in Boston, September 19-21, 1982. From this 'blue sky' effort, I think we will get some inklings of what the next issues are going to be.

$I S U$ : Do you think that the entry of end-users as active participants will be among these new issues?

Wilde: I think that there has been a trend over the last ten years toward getting the delivery system directly to the end-user. I think that we are going to see new technologies that are going to make that process easier. I think that the one major issue that came out of our recent Spring meeting was that there was money to be made by delivering the product to the end-user. In our fall meeting, I am sure that the issues involved in how to do this, in a way that this type of user can apply, will come up.

$I S U$ : As a final part of this interview, are there any concluding remarks you would like to make for our readers?

Wilde: I would like to encourage your readers to participate in ASIDIC activities. The organization allows for vigorous participation and the expression of ideas about our industry and its future. At the moment the information industry is in a vibrant and expansive mode, and we need everyone's ideas. 